\title{
Developments in Additive Manufacturing Processes: Industrial Technologies and Numerical Analyses
}

\author{
M. Chiumenti* \\ * InternationalCenter for Numerical Methods in Engineering (CIMNE) \\ Universidad Politécnica de Cataluña \\ Campus Norte UPC, 08034 Barcelona, Spain \\ e-mail: michele.chiumenti@upc.edu,web-page: http://chiumenti.rmee.upc.edu/
}

\begin{abstract}
In this work the current developments on the numerical simulation of different AM processes are presented. A fully coupled thermo-mechanical framework has been tailored to the analysis of several 3D-printing processes ranging from metal wire feeding to selective melting. The accurate definition of the material deposition is addressed, taking into account actual movement of the heat sourcealong the scanning path as defined for the AM machine. The result is a high-fidelity simulation of the AM process leading to an accurate layer-by-layer building sequence. An advanced high-performance and object-oriented software platform has been enhanced to include the parallel (MPI) FE activation technique used to follow the growth of the geometry according to the fabrication process. The mesh adaptivity strategy makes use of Cartesian voxelization together with octree-type local refinements and global coarsening to keep controlled the total number of elements in the computational domain $^{[1,2]}$. The thermo-viscoelastic-viscoplastic constitutive model introduced is calibrated and the numerical results are validatedthroughan extensive experimental campaign carried out taking advantage of the partnership with several research center such as:ACCESS (Germany), the NorthwesternPolytechnical University (Xi'an, China), the Monash and RMIT Universities (Melbourne, Australia), IK4-Lortek, Leitat, Eurecat (Spain), among others ${ }^{[3,4]}$.
\end{abstract}

\section{REFERENCES}

[1] J. Baiges et al., An Adaptive Finite Element strategy for the numerical simulation of Additive Manufacturing processes, Additive Manufacturing 37 (2021) 101650, https://doi.org/10.1016/j.addma.2020.101650

[2] E. Neiva et al., A scalable parallel finite element framework for growing geometries. Application to metal additive manufacturing, Int. J. for Num. Methods in Engineering, 119 (2019) 1098-1125, https://doi.org/10.1002/nme.6085

[3] X. Lu et al., In situ measurements and thermo-mechanical simulation of Ti-6Al-4V laser solid forming processes. Int.1 Journal of Mechanical Sciences, 153-154 (2019) 119-130, https://doi.org/10.1016/j.ijmecsci.2019.01.043

[4] M. Chiumenti et al., Numerical simulation and experimental calibration of Additive Manufacturing by blown powder technology, Rapid Prototyping J., 23(2) (2017) 448-463, https://doi.org/10.1108/RPJ-10-2015-0136 